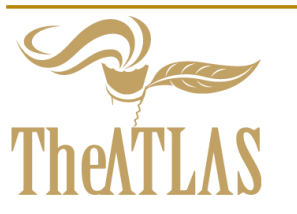

\title{
Integrating Transdisciplinarity in Undergraduate Education
}

\author{
Atila Ertas, Texas Tech University, Mechanical Engineering Department, Lubbock, Texas, 79409, USA, Email: \\ aertas@coe.ttu.edu
}

doi: $10.22545 / 2012 / 00022$

T his study is aimed at a wide audience of students in capstone design classes that cut across multiple fields. In keeping with the dynamic nature of complex problem solving, modern teaching curricula must be designed in ways that help students develop critical thinking and problem-solving skills in both core subjects and new technology-driven content. This paper presents a new methodology in engineering education that is focused on teaching students transdisciplinary skills thereby allowing them to become creative and innovative engineers. This paper also presents an alternative to conventional textbooks in the form of a free, internet-textbook (iTextBook) comprising transdisciplinary learning modules that cut across multiple disciplines. Main objectives of this paper are: to reduce the educational cost burden on students, parents, states and governments, thus helping society; and to teach students innovation skills, educating them broadly and preparing them for an increasingly transdisciplinary, collaborative, and global job market.

\section{Introduction}

"Education should have two objects: first, to give definite knowledge-reading and writing, language and mathematics, and so on; secondly, to create those mental habits which will enable people to acquire knowl- edge and form sound judgments for themselves." 1

"We begin to think about the university as a place of ideas, not as an organization of academic disciplines." ${ }^{2}$

A specific area of study is known as a discipline provided that it has cohesive tools, techniques, and specific methods and a well-developed jargon. As shown in Figure 1-a, disciplines unsurprisingly develop into self-contained hard shells, which lean to minimize interaction with outside units or other disciplines. The longer a discipline evolves, the thicker and tougher its shell becomes. General practitioner of these disciplines develops an effective level of intradisciplinary communication and collaboration due to their well-developed disciplinary jargon. However, the rigid disciplinary shell and the precision of the disciplinary jargon lean to minimize the communication and collaboration among the researchers from diverse disciplines. Thus, from the social sciences point-of-view disciplines develop territories that are intensely defended. Evidently, these territories and disciplinary shells are not in-sync with the move toward the current integration of technology. Today's

${ }^{1}$ The Bertrand Russell Dictionary of Mind, Matter, and Morals, Citadel Press, P. 56.

${ }^{2}$ S. Upham, The Aims of Graduate Education, Keynote Address, Workshop on Global Transdisciplinary Education, and Research, SDPS, Pasadena, CA, June 2001. 


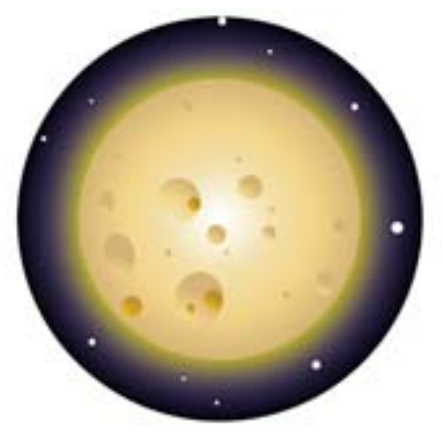

a) Intradisciplinary (within a discipline)

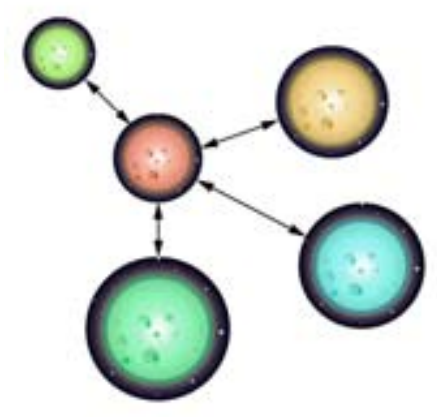

c) Interdisciplinary (among disciplines)

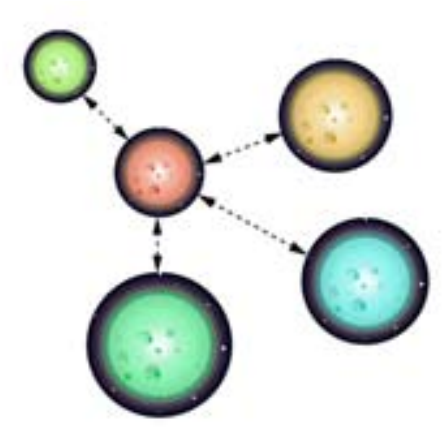

b) Multidisciplinary (among disciplines)

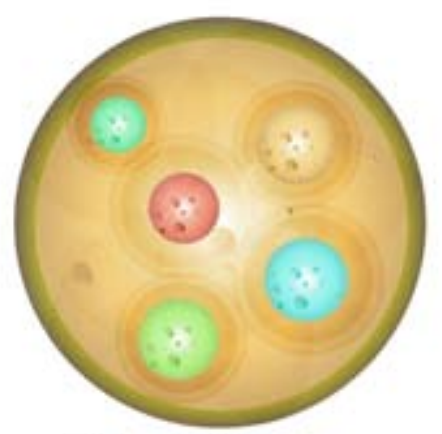

d) Transdisciplinary or Interdisciplinary fusion (beyond disciplines)

Figure 1: From disciplinarity to transdisciplinarity.

problems are not obviously restricted to artificial discipline-oriented boundaries. Times have changed; a massive communication and collaboration infrastructures has helped to tackle on complex problems using larger group of researchers from multiple disciplines.

Multidisciplinary teams and programs have been developed to address common problems that extend across several traditional disciplines. Multidisciplinary activities involve researchers from more than a few disciplines working basically independently, each from their own discipline specific perspective, to solve a common problem. Inadequate and week communication combined with the territorial concerns limit the effectiveness of multidisciplinary efforts. As shown in Figure 1-b, multidisciplinary teams do cross discipline boundaries; however, they remain limited to the framework of disciplinary research.

In Interdisciplinary activities, researchers from various disciplines work jointly on common problems by exchanging methods, tools, concepts and processes among them to find integrated solutions. As shown in Figure 1-c, interdisciplinary activities also overflow discipline boundaries with strong link between them.

As shown in Figure 1-d, in transdisciplinary approach, hard shell of disciplinary boundaries disappeared. Soft disciplinary boundaries intersect each other for open communication and collaboration on a uniform platform that is common to all of them.

This paper presents an alternative to conventional textbook design in an innovative approach to creating free, digital, internet-textbook (iTextBook) transdisciplinary learning modules crossing multiple disciplines, aimed at a wide audience of capstone design classes across fields. In keeping with the dynamic nature of complex problem solving, modern teaching curricula must be designed in ways that help students develop critical thinking and problem solving skills in both core subjects and new technology-driven contents and transdiscipinary contexts. This paper also presents a new methodology in engineering education to teach students transdisciplinary skills to become creative and innovative engineers, integrated into a modular, participatory, and extensible publication format. Students need to be taught new skills for dynamically synthesizing new knowledge in response to new challenges. 
Specific objectives of this study are four-fold: 1) to reduce the educational cost burden on students, parents, states and governments, thus helping society in general and in countries where the cost of print texts work against their adoption; 2) to provide students a deeper understanding of material from multiple domains of expertise; 3 ) to educate students with an ability to adapt to changes and to be able to work at the interface of different disciplines; 4) to teach students innovation skills, educating them broadly and preparing them for an increasingly transdisciplinary, collaborative, and global job market. Objective 1 can be accomplished by providing a free iTextBooks. Objectives 2, 3 and 4 will be accomplished by the inclusion of four core transdisciplinary modules, interactive homework problems, and module projects in the iTextBook.

\section{Transdiscipline}

Over recent years, there has been growing interest among researchers and educators for organized collaboration on the national and international levels. The development of large scale collaborative efforts between researchers from disparate disciplines was spawned from the necessity to increase efficacy in solving complex problems that require knowledge from multiple disciplines. Realizing the benefits from collaborative research, numerous initiatives have been launched to develop transdisciplinary research groups and establish new or larger centers of excellence.

Definitions of transdisciplinary research go back to the early 1970s (Nicolescu, [1], Pohl [2]). Nicolescu (2005) stated that transdisciplinarity concerns that which is at once between the disciplines, across the different disciplines, and beyond all disciplines [3]. Klein (2004) distinguished between the terminology of multidisciplinary, interdisciplinary (ID) and transdisciplinary (TD) approaches as "Multidisciplinary approaches juxtapose disciplinary/professional perspectives, adding breadth and available knowledge, information, and methods. They speak as separate voices, in encyclopedic alignmen...", "Interdisciplinary approaches integrate separate disciplinary data, methods, tools, concepts, and theories in order to create a holistic view or common understanding of complex issues, questions, or problem", and "Transdisciplinary approaches are comprehensive frameworks that transcend the narrow scope of disciplinary world views through an overarching synthesis... [T] he term also connotes a new structure of unity informed by the world view of complexity in science, a new mode of knowledge production that draws on expertise from a wider range of organizations, and collaborative partnerships for sustainability..." [4].

Stokols et al., defined transdisciplinary science as collaboration among scholars representing two or more disciplines in which the collaborative products reflect an integration of conceptual and/or methodological perspectives drawn from two or more fields [5]. Hadorn, H. G et al., stated that: "Transdisciplinary research is research that includes cooperation within the scientific community and a debate between research and the society at large. Transdisciplinary research therefore transgresses boundaries between scientific disciplines and between science and other societal fields and includes deliberation about facts, practices and values" [6]. Rosenfield defined Interdisciplinarity as a process in which researchers work jointly, but from each of their respective disciplinary perspectives, to address a common problem whereas transdisciplinarity is a process by which researchers work jointly to develop and use a shared conceptual framework that draws together discipline-specific theories, concepts, and methods to address a common problem [7].

Gehlert stated that "Transdiscipilinary education that combines exposure to a range of disciplinary knowledge and methods with effective instruction in processes for working on teams to transform knowledge and methods into solutions for complex social problems is the gold standard" [8].

Cronin stated that "There is a need for transdisciplinary research (TR) when knowledge about a societally relevant problem field is uncertain, when the concrete nature of problems is disputed, and when there is a great deal at stake for those concerned by problems and involved in dealing with them. TR deals with problem fields in such a say that it can: a) grasp the complexity of problems, b) take into account the diversity of life world and scientific perceptions of problems, c) link abstract and case specific knowledge and d) constitute knowledge and practices that promote what is conceived to be the common good." [9].

In summary, interdisciplinary and transdisciplinary research they both give integrated solution to a problem in question. Transdisciplinary research includes the key components of interdisci- 
plinarity, along with the incorporation of external non-academic knowledge, applied to solve practical problems. Transdisciplinary research leads to a creation of new paradigms and provides pathways to new frontiers.

Engineering must play a vital role in advancing transdisciplinary efforts, and conversely transdisciplinary efforts will further advance engineering, technology, and science. The prospect of transdisciplinary research is exciting. New networks of researchers can be created in a short time, and other non-traditional participants can become involved in solving the world's problems.

The common threads of all disciplines are notions of design, process and systems (Tanik, et al.,1995) [9]. Design, process and systems (DPS) provide the patterns, the insight, and the judgment necessary to apply knowledge and skills to unstructured problems.

Herb Simon, in the section Holism and Reductionism of his most well-knownl bookThe Sciences of the Artificial [10] eludes the establishment of crucial balance between holistic thinking and mechanistic thinking. There is a clear parallel between disciplinary/ transdisciplinary thinking and reductionism/holism. In the effort of searching for solutions to this dichotomy a realistic approach has been suggested. Noticing the difficulties faced, Simon said, "We are learning that we need a science of complex systems, and we are beginning to construct it" [11]. In The Science of Design chapter of The Sciences of the Artificial [10] he says "The proper study of mankind is the science of design, not only as the professional component of a technical education but as a core discipline for every liberally educated person." Following Simon's lead, we beleive that notions and patterns of design, process and systems are so fundamental that they cut across all disciplines. There is something in these concepts that introduces a greater logical economy in dealing with everyday concrete processes involving engineering activities and business relationships $[12,13]$. The better logical economy is required more these days than any other time in the history of mankind. The reason is apparent in light of the vast expansion of mankind's knowledge base and the speed of introduction of new and exciting technological artifacts. Noticing this extraordinary knowledge expansion we should keep in mind that techniques and methods of the past is needed but not sufficient. A transdisciplinary way of acquiring knowledge means that education, research, development, production, and training are intertwined to produce a better picture and a higher level of abstraction [13].

From the realistic point of view, the systematic study of DPS for their own sake has the likely of providing the essential thinking to maintain intellectual control over the ever increasing information growth; therefore, developing into a scientific discipline. Future engineers or systems integrators, in this framework of integration, will develop functional artifacts and services by considering economical, environmental, social and ethical aspects of human awareness. The transdisciplinary nature of DPS utilization will prove important in improving largely research quality, productivity, and the education of students to build, sustain, and manage the next generation of enterprises as well as their products and services. The first step in achieving transdisciplinary education is to extract the common elements of DPS from existing disciplines and synthesize them into the foundation of the transdiscipline. This extraction process can only be accomplished by broad study of the disciplines with an exclusive goal of identifying the truly common aspects. Once the universal aspects of DPS have been known, they must be woven into the fabric of the transdisciplinary educational model $[12,13]$.

\section{Transdisciplinary Skills and Modules}

As shown in Figure 2, four transdisciplinary core modules and twenty supplementary modules for a capstone design course is proposed. The content of the transdisciplinary core modules will include information and knowledge common to multiple disciplines. The core modules will also include appropriate shared concepts and methods. To provide students a deeper understanding of the material, there will be some content overlap between the core modules as seen from the figure. Students will progressively synthetize the modular information and knowledge as the modules are covered to create a spiral of new knowledge and ideas. As shown in Figure 2, to produce new knowledge, the process of identifying similar knowledge and knowledge integration will take place at the interface of the core knowledge with the existing knowledge.

New knowledge should be generated by the student teams in order to solve a given research project. 


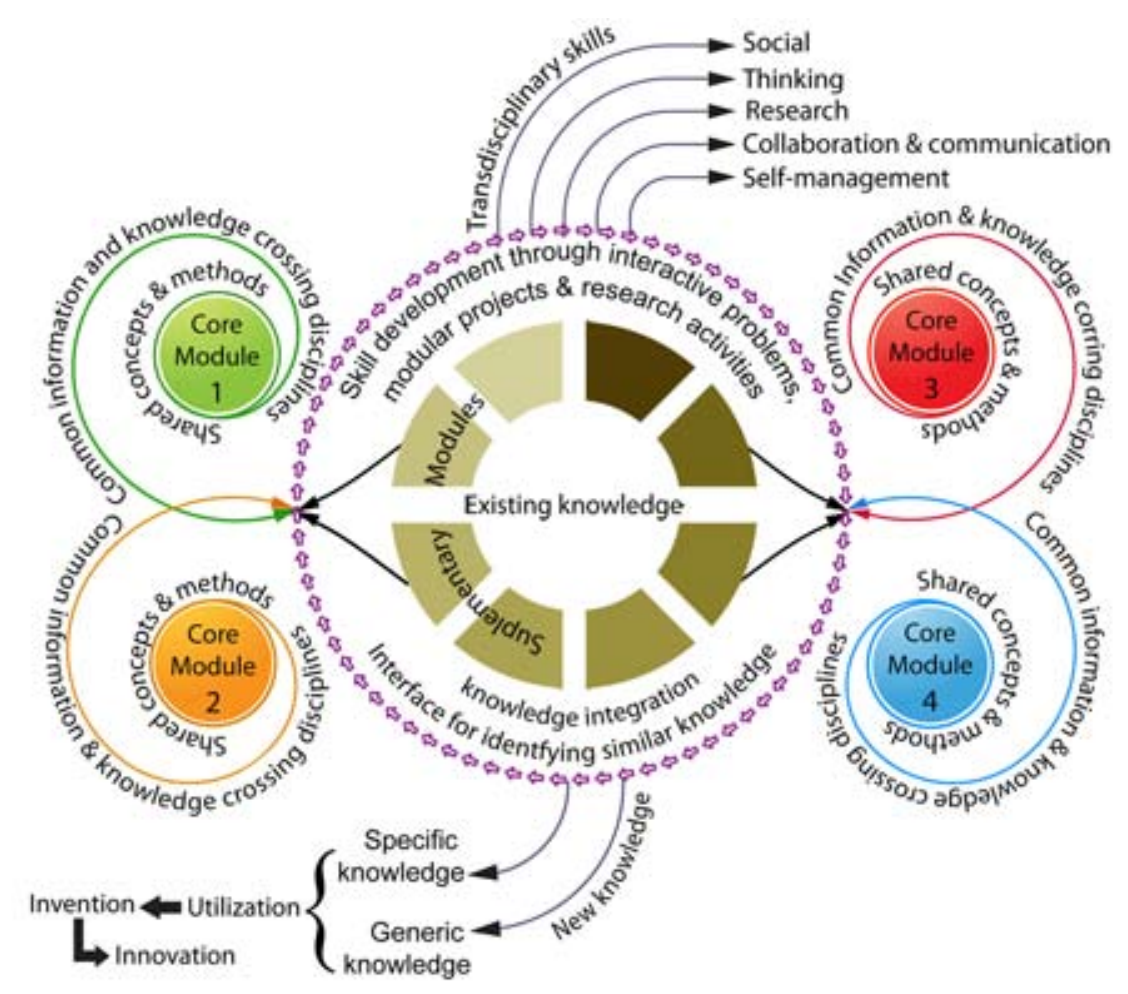

Figure 2: Transdisciplinary skills and new knowledge development process.

The existing knowledge that is available through supplementary modules along with the newly generated context specific knowledge can be applied to solve a specific problem. It should be noted that the solution of a context-specific problem may not be applicable for solving other problems of a similar kind. However, generic knowledge is applicable to solve similar kinds of problems. Generic knowledge enhances the body of knowledge in science and is applicable to solve societal problems [14]. Successful collaborative student teams will be able to bridge between knowledge and invention and ultimately results in innovation.

Students will also develop transdisciplinary skills (see Figure 2) progressively while working on interactive homework problems, performing their modular projects, and collaborating with students on research activities. They will learn, practice, and develop skills as defined in Figure 3 [15]. The success of the research team depends on the team's ability to exploit their most valuable assets: knowledge, transdisciplinary skills, and creativity.

Although the past decade has seen growing interest and investment in transdisciplinary graduate education, undergraduate education remains predominantly dependent upon narrow, disciplinary foci. To prepare students to become transdisciplinary engineers and scientists, engineering programs must start integrating transdisciplinary courses into the undergraduate curriculum. Although researchers have become accustomed to working across disciplinary boundaries, the undergraduate classes offered by many universities have been the same for decades. Transdisciplinary thinking requires integrated broad knowledge from many disciplines which creates different types of talents to discover and solve unstructured problems (need transdisciplinary synergism) with creative and unusual but appropriate ways. Transdisciplinary skills in our students must be set in a rich soil so that the seed can germinate and in time grow into a "student of transdisciplinarians." Undergraduate students should master transdisciplinary competencies before they go on to graduate studies or before they start working.

Dr. Dowling from Harvard University reports that by the year 2050 the average longevity of an American will be around 128 years. If we still retire at 65 years what do we do for the other half of our life time. Age decays our learning skills, particularly our memory and association skills which undergo steep decline. If we do not have these skills in later life, we spend half of our lifetime as useless vegeta- 


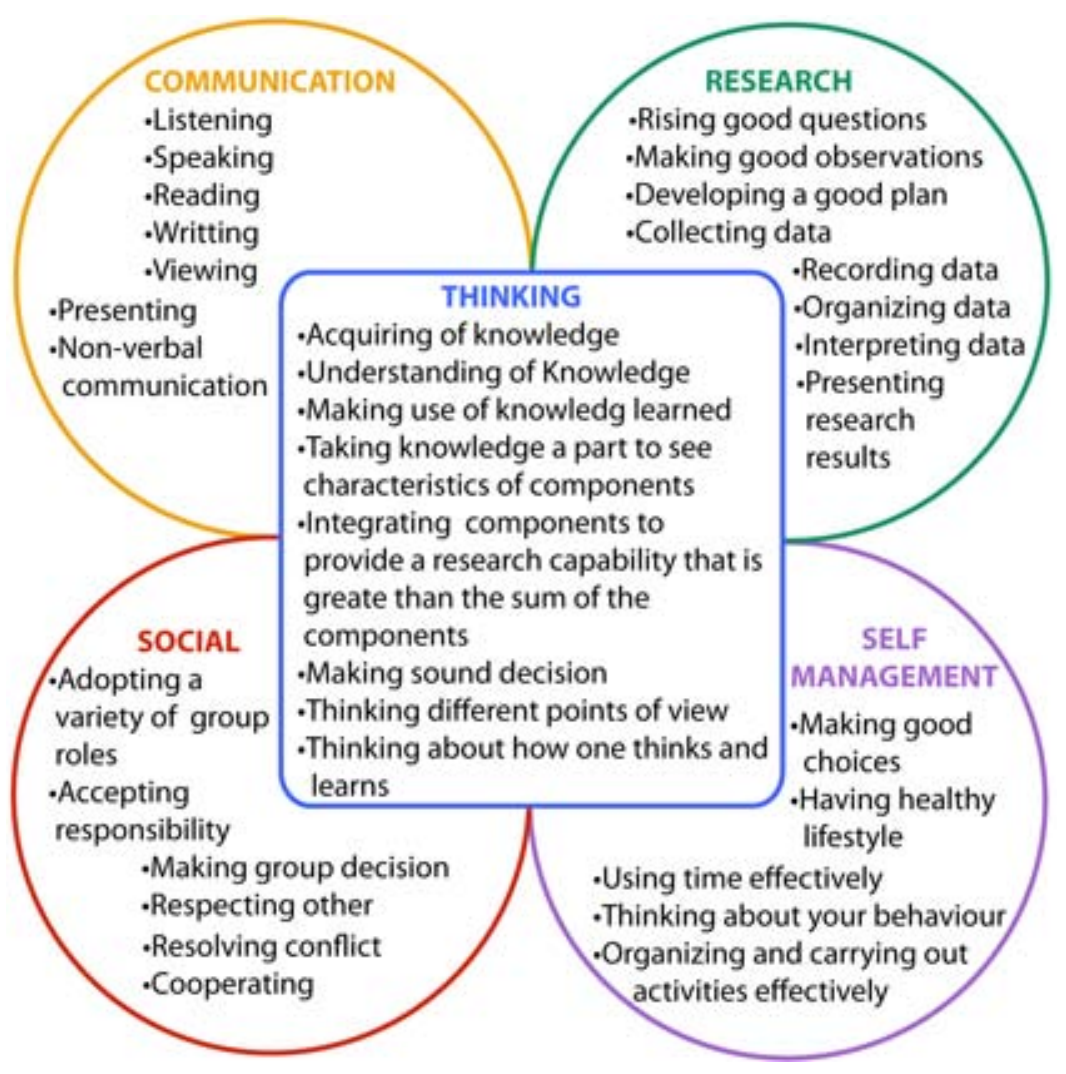

Figure 3: Transdisciplinary skills.

bles. iTextBook process is not only mechanical. Aim of the process is to build skills. iTextBook creates curiosity in students which creates an interest and concentration so that students can absorb information. Consequently, they develop skills. It has been shown critical skills can be turned into habits which remain anchored in us for most of our lives. For example, old man can't find the kitchen in the house but when he is hungry because of the habit automatically goes to kitchen to eat. Therefore, a prerequisite to develop critical skills to help later professional updates and career migrations will be to enhance and reinforce these fading skills earlier in life through awareness, practice and most importantly education [16].

\section{Textbook Costs}

Government studies report a substantial increase in textbook costs. College textbooks can add thousands in cost to a student's education expenses. This is a tremendous financial burden for many students and their families and has a negative impact on federal and state government spending as financial aid providers. Textbook prices "represent a significant barrier to access and persistence." Textbook costs (in 2007) were found to range from $\$ 700$ to $\$ 1000$ per year; textbook prices have risen much faster than other commodities (more than 4 times the rate of inflation [17]); and college aid fails to cover textbook expenses (and many other college costs) [18].

Many faculty members select and assign textbook for their class with little concern to the cost of the textbooks. Often times, students try to find an inexpensive way of obtaining the required textbookborrowing from friend or library, sharing with a roommate, renting, downloading an illegal version, or simply not buying the book. In one survey, 7 in 10 students reported skipped the purchase of a required textbook because of its high cost. Additional complaints about textbook publishing practices included frequent issuance of new editions that prevent use of used textbooks, the packaging of textbooks with CDs, passcodes that expire, and custom editions created for their school [19].

Nevertheless, students recognize that they have to buy the books in order to do well in many classes. Lack of access to textbooks due to cost is even worse 
for disadvantaged students at historically disadvantaged colleges and universities. The high cost of textbooks has a negative impact on improving educational access in the USA.

Equal attention should be paid to the content and quality of textbooks. Modern teaching curricula must be designed in ways that help students develop critical thinking and problem solving skills in both core subjects and new technology driven contents. It is questionable whether today's traditional textbooks, in general, make a positive contribution to learning. How much and how fast can students absorb information from a voluminous (600 to 800 pages) textbook in a one-semester course? Just like loud noise is bad for one's ears, too much information overload is bad for one's brains. This results in developing a short attention span and harms the learning process associated with the science, technology, engineering, and math topics that require deep and sustained mental concentration.

\subsection{Open Educational Resources}

About a decade ago, MIT started free online learning by using the Internet to share the by-products of its campus teaching - including syllabi, lecture notes, assignments, and exams. This effort was initiated to improve learning worldwide, mainly through providing resources to educators, and also as a way to encourage other universities to share their intellectual assets rather than providing them only to those who could afford to pay [20].

Recently, Rice University received funding in the form of grants from the William and Flora Hewlett Foundation, the Bill \& Melinda Gates Foundation, the 20 Million Minds Foundation and the Maxfield Foundation to offer free course materials. Using Rice's Connexions platform, OpenStax (a non-profit publisher) will offer free course materials for five common introductory classes. The grant money is used to hire experts to develop each textbook and to have their work peer reviewed. However, if an instructor decides to use supplementary material from a for-profit company, that would be an additional cost to students [21].

Students can download the OpenCourseWare materials for all the required classes for a four-year degree at Harvard Medical School. One can read all the course materials and take all the quizzes and tests. Moreover, students can even grade themselves. However, students cannot get a degree from Harvard- not unless they pay tuition. Similar arguments can be made for recent MIT and Stanford initiatives [22]. Obviously, if students are not seeking for a degree they have the potential for a huge benefit from a good OpenCourseWare program. For this proposed study, the goal is not only to provide free modular textbooks or courseware but more fundamentally to change the textbook content, design and development to improve student learning. Through the proposed study, professors and instructors will have the freedom to design and customize a textbook with respect to the needs of different students, such as majority, average, or disadvantaged students. The students will design and develop their own modular projects and will provide solution(s) collaboratively to produce new knowledge. The inclusion of transdisciplinary core modules will teach the students the conceptual foundations of transdisciplinarity. Ultimately, students will learn conceptual and methodological strategies designed to enhance the processes and outcomes of collaborative, team-based research to address important practical problems.

\section{Creating iTextBook}

As the pace of improvement of new technical systems has sustained to accelerate, the necessitate has shifted from interdisciplinary or multidisciplinary design teams to trans-organizational and transnational work. During the last decade, the number of complex problems facing engineers has exploded, and the technical knowledge and understanding in science and engineering required to strike these problems is speedily evolving. A few examples are the innovative advancements in semiconductor technologies, software technologies, the biosciences, and nanotechnology. The last two decades of designing large-scale science and engineering systems educated us that neither disciplinary, nor multidisciplinary or interdisciplinary approaches provide an environment that promotes the collaboration and synthesis necessary to extend beyond existing disciplinary boundaries [23].

As mentioned earlier, the essence of transdisciplinary engineering and science lies in the common ground built on the foundation of design fundamentals, process development, and systems design. The core of design, process, and systems knowledge is broad, incorporating concepts and methods from 


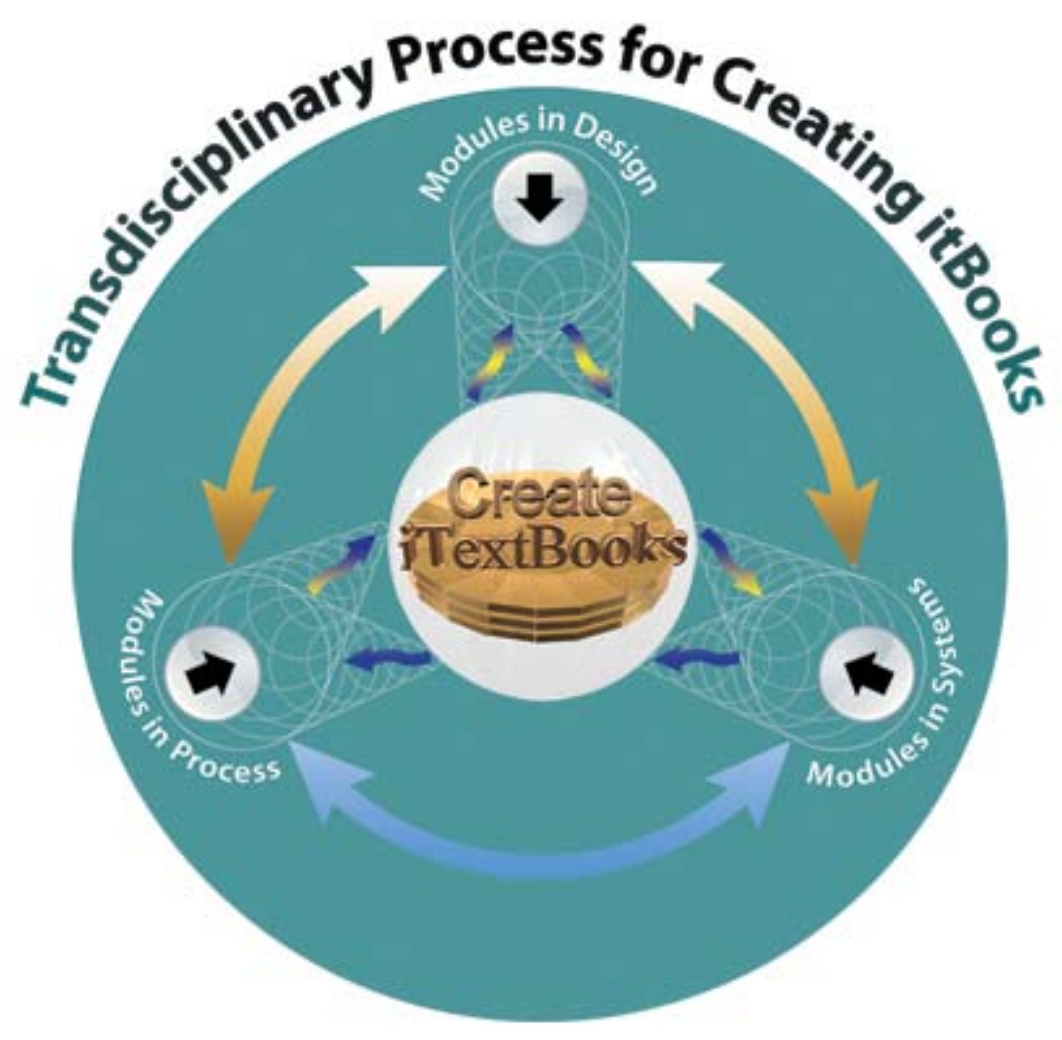

Figure 4: Process for creating iTextBooks.

many different disciplines. A sound transdisciplinary engineering and science needs, of course, to incorporate knowledge from many different areas. Therefore, as shown in Figure 4, in the proposed process for the creation of iTextBook, the core of knowledge areas centered on design, process, and systems will be augmented with peer-reviewed supplementary modules. The modules will be clustered in the three categories; yet, these three categories are interconnected. In fact, some of the modules in them could be stored in two or three of the categories.

Modules will be designed to be stand-alone, and professors, instructors will be able to assemble custom and focused content for students. This focused approach will help students master the most pertinent and applicable subject matter. The process for creating iTextBooks, as shown in Figure 4 is creative, interactive, and dynamic. The iTextBook process is configured to present subject matter options for the creation of modules that are stored in a database. The module database can contain the newest and most common modules used across several disciplines. The modules selected for creating iTextBooks are dynamically revised to keep them up to date. iTextBook will have the characteristics of adaptability (make the module content flexible to meet the learning outcomes and learning style of different students), personalizability (each student is different - an iTextBook can be assembled for the majority of students, for average students, for disadvantaged students, or for individual students), and customizability (the iTextBook content can be customized for different disciplines). Modules that are not updated can be eliminated from the database or sent to the authors for revision at any time. The revision of one or more modules is far more efficient than revising an entire textbook and publishing a new edition.

Objectives 2, 3 and 4 will be accomplished by the inclusion of four core transdisciplinary modules, interactive homework problems, and module projects in the iTextBook as described below.

\subsection{Modular Projects}

The iTextBook, representative of textbooks of the future, will promote project-based-earning. Instead of assigning the students to solve already established homework problems to students, professors and instructors will assign modular projects to be conceived 
and developed by student groups to reinforce fundamental concepts and to generate innovating projects. This will shift students' efforts away from some of the homework problems at the end of traditional textbook chapters. As an alternative to traditional homework problems, students will be allowed to develop their own research-based, open-ended modular projects and propose solutions. Modular projects enhance the content. Besides teaching module content, the open-ended modular projects can teach students critical and creative thinking skills. By developing and solving modular projects, students can create things outside the box. Namely, students already know something, but instructors want them think beyond and above what they know to produce new knowledge. The process of developing modular project is not only rote. The aim of the process is to develop skills and habits to strengthen the students' abilities in terms of teamwork and leadership.

\subsubsection{Requirements to Design Modular Projects}

To complete each module, student project teams will be assigned a modular project, which will integrate most of the fundamental concepts of the module that students have learned. Since design, process, and systems are envisioned as the essence of the transdisciplinary concept, each module will have three following modular project requirements: 1 . Design requirements, 2. Process requirements, and 3. System requirements. Students must follow the generic modular project requirements to design and develop their modular projects. Some examples are:

- Identify the important parameters affecting solution decisions;

- Investigate which parameters affect the solution most;

- Relate the modular project to human health, security, disasters (water crisis, food crises, earthquakes, tornadoes, tsunamis, and flood), economics, business, management, etc;

- Relate the modular project to sustainability (addressing environmental, economic, social aspects);

- Relate the modular project to complexity (natural, social, humanities, engineering);

- Consider functional requirements, ethical issues, safety issues, and contemporary issues;
- Evaluate and report the following transdisciplinary attributes [24]: project design, development, and implementation; knowledge integration/synthesis; new knowledge generation; collaboration (the interaction of social and cognitive factors in collaboration and teamwork); management and leadership, networking; creativity and Innovation; research and bibliometric measures (literature search, new findings, paper publications, etc.).

If the modular project involves system thinking, that should be also clearly stated. Students must show each and every step of the solution process. Requirements will be clearly stated at the end of the module by the author of the module to guide students to design their modular projects.

It is important to note that the final modular project will be the cumulative result of the modular projects given previously. This process will provide a progressive approach for designing and developing modular projects and knowledge synthesis. Therefore, the modular approach to presenting the materials will provide a mechanism and opportunity for the students to combine knowledge from multiple modules and promote the skills of finding and integrating tools and methods from what have traditionally been separate knowledge areas.

\subsection{Introducing Interactive Homework Problems}

To facilitate a deeper understanding of the material, besides traditional homework problems, interactive homework problems will also be included in the appropriate modules. Interactive problems will help students develop problem-solving strategies that are based on conceptual understanding, rather than equation manipulation. These interactive problems can be manipulated by the students to explore the effects of parametric changes on the problem. Interactive process promotes more fundamental and generalizable understanding of the material, as opposed to "cook book" approaches that instill pattern matching between chapter examples and homework or exam problems.

\subsection{Implementation}

The scope of possible module subjects spans the curriculum and encompasses the sciences (physical, 
social, and biological), engineering, medicine and heath, philosophy, technology, mathematics, arts and the humanities. Examples of some generic module topics include, but are not limited to social systems, natural systems, life-support systems (atmosphere, water and food), ecology, life processes, process science, cognitive process, mental process, process modeling, process ontology, design process, engineering design, science and design, healthcare design, biodesign, energy, safety, sustainability, environment, economy, business, management, complexity, education, ethics, collaboration, communication and many others.

However, for this study, transdisciplinary iTextBooks for the first part of the capstone engineering design course will be proposed to be used by all the engineering disciplines as well as those from other scientific disciplines such as environmental science, economics, and business. Capstone design courses integrate knowledge, concepts, and skills associated with the whole sequence of study in a program. Although the idea of including a capstone course in a degree program is not new, the format of capstone design courses changes considerably among different disciplines $[25,26]$. The two-semester sequence of capstone design courses at the Texas Tech University in the Mechanical Engineering Department has the objective to better prepare graduates for engineering practice. In the first semester of the capstone design sequence (ME 4370, Design I), design problems characteristic of engineering are used to introduce students to the engineering design process. Topics covered and associated exercises include problem formulation, design requirements and specifications, project management, concept synthesis, decision making approaches, analytical considerations of cost, design optimization, codes and standards, engineering communication, ethics, environmental considerations, and sustainability. In the following semester, the second part of the capstone design sequence (ME 4371, Design II) utilizes industry-level team projects to prepare students with important design, implementation, communication, and presentation experience. The following twenty-four modules that cut across engineering disciplines for the first part of the capstone design course are proposed.

\subsubsection{Transdisciplinary Core Modules}

- Transdisciplinarity and Complexity (1): A practical foundation for complexity is presented that enables an engineering system's complexity to be evaluated against its functions and qualitative factors, such as social mores and human values. The course covers a) definitions and characteristics of complexity; b) modeling of complex systems; c) tools and methods for managing complex systems; d) strategies for reducing complexity; and e) transdisciplinary applications of complexity theory.

- Transdisciplinary Sustainable Design and Development (2): Transdisciplinary methodologies to guide research, policy and action towards sustainability will be covered. Students will learn broad research skills and knowledge in strategies for sustainable integration, sustainable resource use and management, environmental conflict resolution, policy formulation and decision-making. Using case studies, interconnectivity of environment, economy and society will also be discussed.

- Transdisciplinary Training and Research Process (3): The focus of this course is to enable the students working jointly with others representing diverse disciplines. This course covers: generic design; collaborative activities, conflict resolution; practice and research ethics, transdisciplinary research process using a system of systems approach; impact of social issues on design; generic activity-based transdisciplinary research process framework; the role of experts in transdisciplinary research processes and transdisciplinary case studies.

- Transdisciplinary System and Product Development (4): System/product development involves product planning, technology planning, requirements engineering, concept development and selection, design elaboration, process design, implementation and testing as well as management of various resources. This module teaches transdisciplinary system and product development methods, techniques and tools so that engineers can have a big picture view of the whole system/product life and use systematic approaches to design and development of products and systems.

\subsubsection{Supplementary Modules}

- Design Category: Design Analysis for Materials 


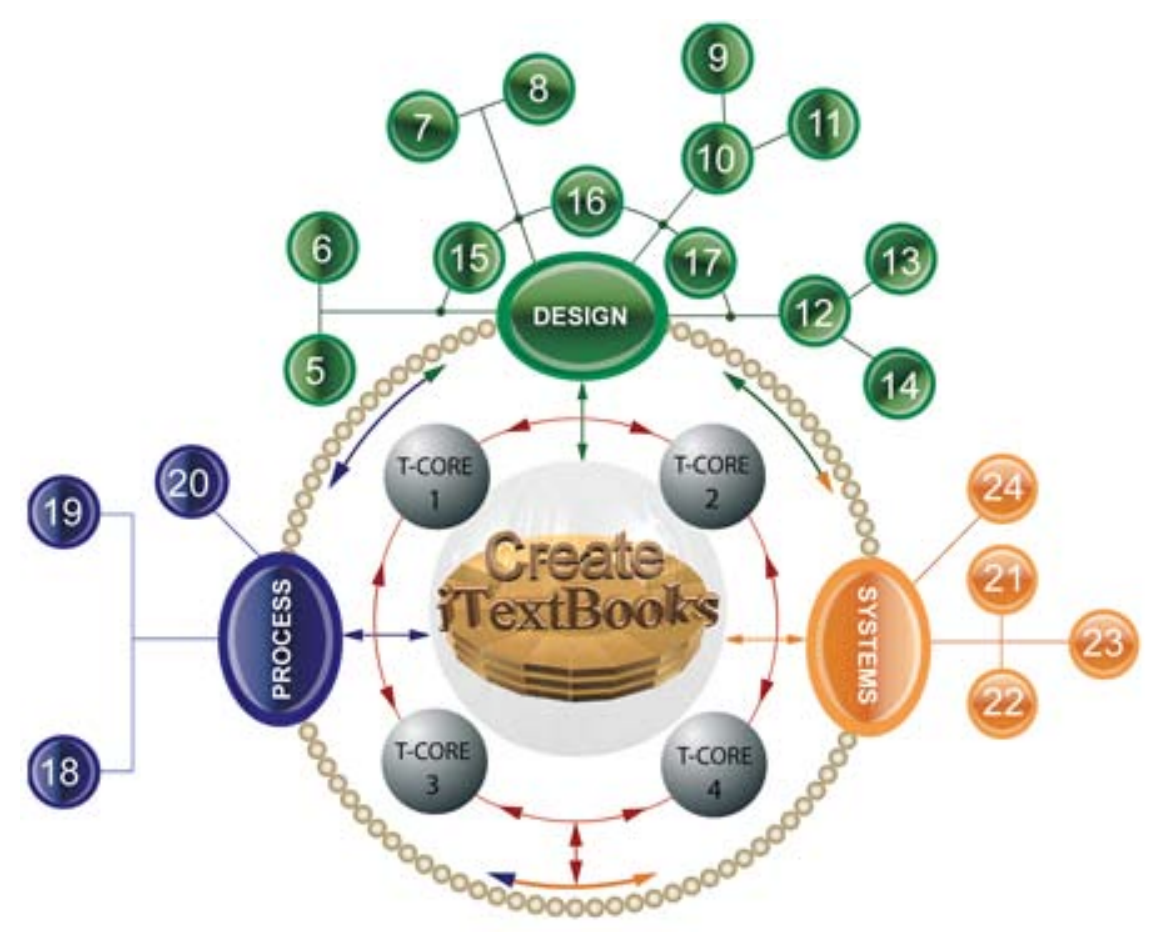

Figure 5: Network of modules.

Selection (5), Prevention through Design (6), Environmental Psychology (7), Environmental Design (8), Bio-Design (9), Nano-Tech Design (10), Healthcare Design (11), Modeling and Simulation (12), Reliability and Safety (13), Optimization (14),Innovation and Creativity (15), Engineering Ethics (16), Project Financial Modeling \& Management (17).

- Process Category: Statistical Decision Making Process (18), Risk Analysis and Assessment Process (19), Entrepreneurship (20).

- Systems Category: Systems theory and thinking (21), Social Systems Design (22), Systems of Systems (23), Collaboration, Communication, and Teamwork (24).

Figure 5 shows the network of twenty-four modules and their relationships. From the network given in Figure 5, instructors can create several different kinds of iTextBooks for different students from different disciplines for capstone design courses. The inclusion of core modules will teach students the transdisciplinary skills required to identify, frame, and address important practical problems that cut across disciplinary boundaries. Because the transdisciplinary core modules are focused and independent, they can also be mixed and matched with other courses or integrated into the redesign of an entire curriculum.

\section{Expected Learning Outcomes}

The expected learning outcomes that will result from this project will be:

1. to provide students a deeper understanding of the material,

2. to educate students with an ability to adapt to changes and to be able to work at the interface of different disciplines,

3. to teach students innovation skills,

4. to educate the students broadly and to prepare them for an increasingly transdisciplinary, collaborative, and global job market, and

5. to teach transdisciplinary skills to identify, frame, and address important practical problems that cut across disciplinary boundaries.

\section{Assessment and Evaluation Plan}

The process for defining, assessing and evaluating learning outcomes is shown in Figure 6. 


\subsection{Formative Assessment}

Formative assessment will be conducted: by goal setting to create clear expectations, by observations to verify student understanding, by questioning to give opportunity to students demonstrate what they have learned, by given very short essay question to project teams which will demonstrate collaborative activities, and by student record keeping to help students better understand their own work [27, 28]. Since formative assessment will provide feedback to students, it may not be used as an evaluation tool.

\subsection{Summative Assessment}

Summative assessment process will be conducted at the beginning, at the midterm, and also at the end of the class in order to judge student's overall performance and to determine whether long-term learning goals have been met. This process will include continuous assessment tasks during the entire one semester class period. Summative assessments tools will include:

1. pre-test,

2. modular projects,

3. interactive homework problems,

4. midterm exam,

5. final integrated modular project,

6. final exam (includes post-test), and

7. survey, and

8. exit interview.

Evaluation will be a collaborative activity between teachers and students. Students will assume an active role in evaluation so they can begin to develop individual responsibilities for development and selfmonitoring. To accomplish this goal, a survey will be developed to assess student opinions about the usefulness of the proposed concept and to collect standardized information through structured questionnaires to generate quantitative data.

Survey questions will be developed using the learning outcomes (defined previously) and also using the main factor requirements stated as follows: Five treatments (main factors) to be compared in the analysis are: (1) Introducing transdisciplinary core modules (treatment A), (2) Introducing modular projects (treatment B), (3) Introducing interactive problems (treatment C), (4) Introducing transdisciplinary project collaboration (treatment D), and (5) Introducing the process of integrative teamwork (treatment E).

\subsection{Statistical Approach for Survey Data Analysis}

One Way ANOVA will be used to test hypotheses regarding the equality of the main factors (treatments) [29]. The basis of ANOVA is the partitioning of the sum of squares into between-treatments sum of squares, $S S_{\text {between }}$ and within-treatments sum of squares, $S S_{\text {within }}$. This will facilitate comparisons of observations simultaneously rather than individually. In this analysis, we will assume that samples are normally distributed. $F$ test defined by Equation (1) will be used to evaluate the null hypothesis.

$$
F=\frac{M S_{\text {betwee }}}{M S_{\text {within }}}
$$

Since there are more than two treatments (in this case, 5) of independent variables, statistical analysis will be carried out in two steps:

Step 1. Perform the $F$ test to determine if any significant differences exist among any of the means. If the $\mathrm{F}$ test value shows statistically significant, then carry out the second step.

Step 2. In the second step, a post-hoc analysis will be performed to determine where the inequalities are. A post-hoc test is used when there are three or more means to compare. This test provides us the critical difference between all possible two means. For this study, Fisher's Protected t-test will be used. The formula is given by:

$$
F_{\text {compare }}=\frac{\left(M_{i}-M_{j}\right)^{2}}{M S_{\text {within }}\left(\frac{1}{n_{i}}+\frac{1}{n_{j}}\right)}
$$

Where $i$ and $j$ are the treatments being compared, and $n$ and $M$ are the number of observations and the mean of treatment, respectively. The test statistics will be performed for each pair of means by using the values of $F_{\text {compare }}$ and $F_{c r}$. The critical value of $F_{c r}$ is determined from statistical tables using the degree of freedom between treatments and the degree of freedom within the treatments' values. The calculation of the values of $F_{\text {compare }}$ and $F_{c r}$ will guideus to make a decision whether question \#1 is statistically significant and which treatment is the less or most dominant factorto provide students a deeper understanding of the material. 


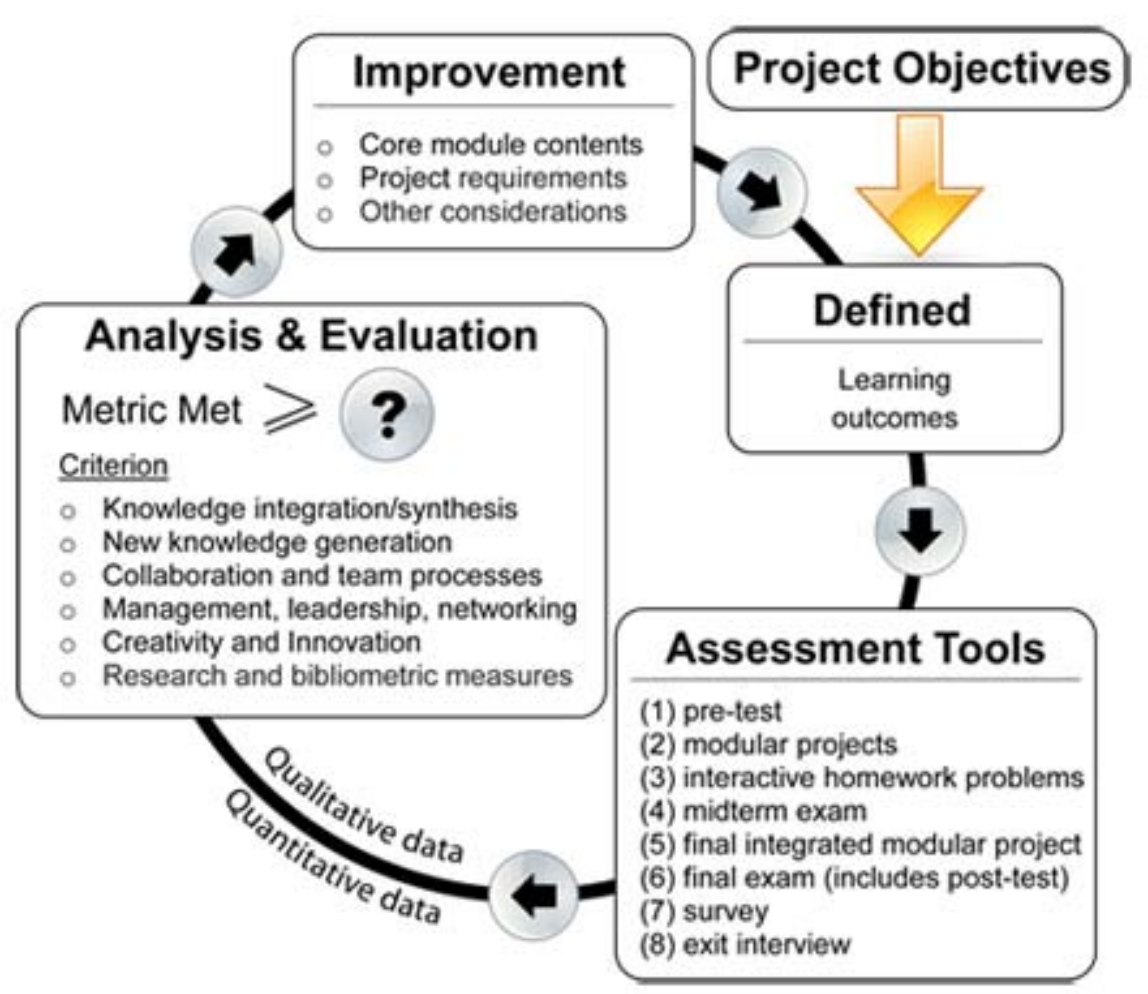

Figure 6: Process of assessment/evaluation.

\subsubsection{Development of Survey Questions}

Now, consider the learning outcomes defined in Section 6 and the main factors (treatments A, B, C, D and $\mathrm{E}$ ) for the ANOVA analysis. For example, Question \#1 corresponds to the first learning outcomes with 5 treatments defined previously. Then, survey question \#1 should read as:

Which treatment is significant to provide students a deeper understanding of the material. Place a 1 next to the item that is least important and place a 5 next to the item that is most important.

— Introducing transdisciplinary core modules (treatment A)

— Introducing modular projects (treatment B)

— Introducing interactive examples (treatment C)

— Introducing transdisciplinary project collaboration (treatment D)

— Introducing the process of integrative teamwork (treatment E)

\subsubsection{Pre-Test and Post-Test}

At the beginning of the class, students will be randomly assigned to modular project teams to eliminate selection bias. This process will allow one to measure not only differential gains between groups, but also absolute gains in skills and knowledge. Each student will take a conceptual design project as a pre-test upon entry into the capstone design course. This special conceptual design project will be developed in a way that the solution(s) will require all the transdisciplinary characteristics, skills, and tools for innovative design solutions. The same conceptual design project will be given as a post-test as a part of the final exam. The comparison of pre-test and post-test will provide concrete data that could be scored and analyzed to see whether there is a gain in student learning pertaining to transdisciplinarity.

The results of the modular and final integrated modular projects can be compared for each student team to determine average gains in student learning in transdisciplinary skills. Interactive homework problems, midterm and final exam questions can be analyzed to determine the students understanding of the fundamental concepts. This analysis can be conducted by using rubrics similar to the one used to 
Table 1: Criteria for determining transdisciplinarity

\begin{tabular}{|c|c|}
\hline $\begin{array}{l}\text { Indicators to Measure } \\
\text { Transdisciplinarity }\end{array}$ & Degree of Indication \\
\hline $\begin{array}{l}\text { Deeper understanding } \\
\text { of the material }\end{array}$ & $\begin{array}{l}\text { Check: midterm and final exams; interactive problem solutions to what } \\
\text { degree and how correctly methods and fundamental concepts are used. }\end{array}$ \\
\hline Transdisciplinary skills & $\begin{array}{l}\text { Check: social, thinking, research, communication, and } \\
\text { self-management skills. }\end{array}$ \\
\hline knowledge integration & $\begin{array}{l}\text { Check: whether the content of the research outcomes reflect knowledge } \\
\text { integration; diversity of knowledge sources; sharing from different } \\
\text { sources; how many of the integrative steps set out and how well the } \\
\text { steps were carried out [31]. }\end{array}$ \\
\hline $\begin{array}{l}\text { Generation of new } \\
\text { knowledge that } \\
\text { transcends disciplinary } \\
\text { boundaries }\end{array}$ & $\begin{array}{l}\text { Check: content of the research outcome; what kind of existing data and } \\
\text { information are used to transform them into a new knowledge; } \\
\text { knowledge assets such as intellectual capital; value of new knowledge } \\
\text { (technical, economic and social). }\end{array}$ \\
\hline $\begin{array}{l}\text { Collaboration and } \\
\text { team processes }\end{array}$ & $\begin{array}{l}\text { Check: practice of collaboration of the project teams with different } \\
\text { disciplines; interaction of social and cognitive factors in collaboration } \\
\text { and team work; transdisciplinary behavioral patterns of project team } \\
\text { members; use of external experts. }\end{array}$ \\
\hline Innovation & $\begin{array}{l}\text { Check: capture of new physical phenomena; bootstrapping of existing } \\
\text { technologies; use of disruptive technology; patent system. }\end{array}$ \\
\hline Creativity & $\begin{array}{l}\text { Check: number of concepts generated (fluency); diversity of concepts } \\
\text { generated (flexibility); originality of concepts generated (originality); } \\
\text { check amount of detail of concepts (elaboration). }\end{array}$ \\
\hline $\begin{array}{l}\text { Management, } \\
\text { leadership and } \\
\text { networking }\end{array}$ & $\begin{array}{l}\text { Check: how well the organizational structure fosters communication; } \\
\text { networking among group members and project teams; joint work } \\
\text { activities and shared decision making; leadership tasks (cognitive tasks, } \\
\text { structural tasks, and process tasks). }\end{array}$ \\
\hline $\begin{array}{l}\text { Research and } \\
\text { bibliometric } \\
\text { indicators }\end{array}$ & $\begin{array}{l}\text { Check: literature search, diversity and the co-authorship of the } \\
\text { references publications used, content of the research outcome, possible } \\
\text { paper resulted from the modular project; research benefit to society. }\end{array}$ \\
\hline
\end{tabular}

analyze the modular and the final integrated modular projects results. Moreover, a group of students can be interviewed after the course is over to understand their preconceptions and misconceptions about the material covered in transdisciplinary core modules.

Table 1 shows criteria for determining transdisciplinarity. Although means for evaluating transdisciplinary processes are a big challenge due to their multidimensional character, Table 1 can provide reasonable conceptual framework measures for transdisciplinary evaluation $[24,30,31]$.

\section{Conclusions}

With the challenges discussed above in mind, consider the future of U.S. higher education. One need is for customizable content. With modular textbooks, professors or students can dynamically assemble suitable content that is most up-to-date.

The high price of textbooks is a tremendous financial burden for many students (especially economically disadvantaged students in U.S., students at the historically disadvantaged colleges in U.S. and in non-industrial nations) and their families and has a negative impact on federal and state government spending as financial aid providers. One of the key aims of this proposal is making a contribution to the community and society as well as making an impact in education. It is believed that the curriculum improvements that will result from this project will have significant impacts on undergraduate engineering education. iTextBooks will have the charac- 
teristics of adaptability (make the module content flexible) to meet the learning outcomes and learning style of different students), personalizability (each student is differentan iTextBook can be assembled for the majority of students, for average students, for disadvantaged students, or for an individual student and customizability (the iTextBook content can be customized for different disciplines).

The biggest impact of the project will be seen when iTextBooks are made freely available to the world academic community and trans-sector organizations in the public and private sphere (the target is approximately 70,000 engineering seniors in the U.S. as well as those from other scientific disciplines such as environmental science, economics, business and in countries where the cost of print texts work against their adoption).

The digital nature of these texts allows for the incorporation of interactive homework problems in each module. These problems can be manipulated by the students to explore the effects of parametric changes on the problem. This promotes a more fundamental, generalizable understanding of the material, as opposed to "cook book" approaches that consist of pattern matching between examples and homework or exam problems.

The text books of the future will promote projectbased learning. Students will work on projects that apply the concepts learned in each module to realworld problems. Students will be motivated to learn the material because they can immediately see the importance of the concept for dealing with real-world context and situations. Moreover, the projects will promote a deeper understanding of the material of each module through requiring the students to synthesize new knowledge in the form of implementations of the concepts and tools.

Finally the modular approach to presenting the materials will provide a mechanism and opportunities for the students to combine knowledge from multiple modules and promote the skills of finding and integrating tools and methods from what have traditionally been separate knowledge areas.

The Academy of Transdisciplinary Learning and Advanced Studies (TheATLAS) will work together with many international distinguished scientists and engineers to accomplish this important project.

\section{Acknowledgements}

The author extends his sincere gratitude to Professor Ramamoorthy for his insightful help and encouragement for this project. Also, the author would like to extends his sincere appreciation to Dr. Julie T. Klein and Dr. Derrick Tate for their valuable comments on this study.

\section{References}

[1] Nicolescu B., 2010. Methodology of Transdisciplinarity - Levels of Reality, Logic of the Included Middle and Complexity. The ATLAS TransdisciplinaryTransnational-Transcultural Bi-Annual Meeting, TheATLAS Publications, Georgetown, TX, pp. 1-14.

[2] Pohl C., 2010. From Transdisciplinarity to Transdisciplinary Research. The ATLAS TransdisciplinaryTransnational-Transcultural Bi-Annual Meeting, TheATLAS Publications, Georgetown, TX, pp. 1521.

[3] Nicolescu, B., 2005. Toward Transdisciplinary Education and Learning. Science and Religion: Global Perspec-tives. pp. 1-12.

[4] Klein, J.T. 2004. Disciplinary origins and differences. Fenner Conference on the Environment: Understanding the population-environment debate: Bridging disciplinary divides. Canberra, AU pp.10 of 20. http://www.science.org.au/events/fenner/klein. htm.

[5] Stokols D., Harvey R.G., Fuqua J., Phillips K., 2004. In vivo Studies of Transdisciplinary Scientific Collaboration, Lessons Learned and Implications for Active Living Research. American Journal of Preventive Medicine, 28 (2), pp. 202-213.

[6] Hadorn, H. G., Biber-Klemm S., GrossenbacherMansuy W., Hirsch Hadorn G., Joye D., Pohl C., Wiesmann U., and Zemp E. 2008. Handbook of Transdisciplinary Research, Enhancing Transdisciplinary Research: A Synthesis in Fifteen Propositions. Chapter 29, p. 435.

[7] Rosenfield P.L., 1992. The potential of transdisciplinary research for sustaining and extending linkages between the health and social sciences. Soc Sci Med., 35, pp. 1343-1357.

[8] Gehlert S., 2012. Shaping Education and Training to Advance Transdisciplinary Health Research. Transdisciplinary Journal of Engineering \& Science, 3, pp. $1-10$. 
[9] Cronin, K. 2008. Transdisciplinary Research (TDR) and Sustainability. Environmental Science and Re search (ESR) Ltd. http://learningforsustainability .net /pubs/Trans- disciplinary_Research_and_Sus tainability.pdf, accessed: August 12, 2012.

[10] Simon, H. A., 1999. The Sciences of the Artificial. Third Edition, The MIT Press, (First Edition published in 1969).

[11] Simon, H. A., 2000. Keynote Speech. Integrated Design and Process Technology Conference, Society for Design and Process Science and Software Engineering Society, Dallas, TX.

[12] Tanik, M. M., Yeh, R. T., and Ertas, A.,1995. Integrated Design and Process Strategies. SDPS, The First World Conference on Integrated Design and Process Technology, Integrated Design \& Process Technology Proceedings, 1, pp. 511-514.

[13] Ertas, A., M. M. Tanik, and T. T. Maxwell, 2000. Transdisciplinary Engineering Education and Research Model. Journal of Integrated Design and Process Science, 4(4), pp. 1-11.

[14] Tress, B., and Fry, G. Defining Concept and the Process of Knowledge Production in Itegrative Research. http://library.wur.nl/frontis/landscaperesearch/02-tress.pdf, accessed: August 18, 2012.

[15] Transdisciplinary Skills, http://www.amersol.edu.pe /es/pyp/PYPskills. asp, accessed: August 18, 2012.

[16] From C. V. Ramamoorthy's notes, 2012. University of Berkeley, CA, USA.

[17] The High Price of Textbooks. http://www. afforda book.com /high-price.php, accessed: August 7, 2012.

[18] Student Public Interest Research Groups, 2007. http://www.studentpirgs.org/news/governmentreport-finds-textbook-costs-still-skyrocketing, accessed: August 7, 2012.

[19] Redden M., 2011. 7 in 10 Students Have Skipped Buying a Textbook Because of Its Cost, Survey Finds. The Chronicle of Higher Education. http://chronicle.com/article/7-in-10-StudentsHave-Skipped/128785/, accessed: August 7, 2012.

[20] Carson S., 2012. MIT OpenCourseWare in the New Era of Online Learning. bridges Magazine, 34, July. http://www.ostina.org/index.php?option $=$ comcontent\&view $=$ article\&id $=5952 \&$ Itemid $=3378$, accessed: Aug. 7, 2012.

[21] Smith M., 2012. Why Pay for Intro Textbooks? Inside Higher Ed. http://www.insidehighered.com /news/2012/02/ 07/rice-university-announces-opensource-textbooks, accessed: Aug. 7, 2012.

[22] Williamson J., 2007. Open Courseware: How You Can Take Classes at MIT, Stanford, or Harvard for Free. http://www.distance-education.org/Articles /Open-Courseware-How-You -Can-Take-Classes-atMIT Stanford-or-Harvard -for-Free-45.html, accessed: Aug. 7, 2012.

[23] Ertas, A., Gatchel, S., Rainey, V., Tanik, M. M., 2007. A Networked Approach to Transdisciplinary Research and Education. TheATLAS Publication, TAM-2007, 3(2), pp. 1-12.

[24] Klein J.T., 2008. Evaluation of Interdisciplinary and Transdisciplinary Research. American Journal of Preventive Medicine, 35, pp. 116-123.

[25] Brandon D, Pruett J., Wade J., 2002. Experiences in Developing and Implementing a Capstone Course in Information Technology Management. Journal of Information Technology Education, 1(2), pp. 91-102.

[26] Todd R. H., Magleby S. P., Sorensen C.D., Swan B. R., Anthony D. K., 1995. A Survey of Capstone Engineering Courses in North America,. Journal of Engineering Education, pp. 165-174.

[27] Formative Assessment Tools. http://www.ehow.com /list-7421475-formative-assessment-tools.html, accessed: Aug. 12, 2012.

[28] What Are Formative Assessments and Why Should We Use Them? http://www.scholastic.com /teachers /article/what-are-formative-assessments-andwhy-should-we-use-them, accessed: Aug. 12, 2012.

[29] Ertas A., Jones J.C., 1996. The Engineering Design Process, Second edition. New York: John Wiley \& Sons, Inc.

[30] Mackey J.L., 2001. Another approach to interdisciplinary studies. Issues in Integrative Studies, (19), pp. 59-70.

[31] Newell W.H., 2006. Interdisciplinary Integration by Undergraduates. Issues in Integrative Studies, (24), pp. $89-111$.

\section{About the Author}

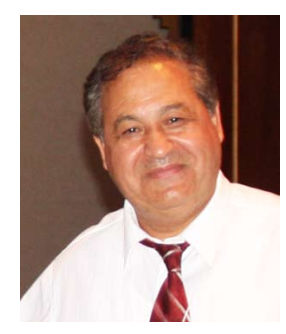


Dr. Atila Ertas is a Professor of Mechanical Engineering and Director of Transdisciplinary Ph.D. Program on Design, Process and Systems. Ertas is author/co-author of four books and co-editor of more than 35 proceedings. He has been teaching capstone design classes for more than 25 years. He is a Senior Research Fellow of the $\mathrm{IC}^{2}$ Institute at the University of Texas Austin, a Fellow of American Society of Mechanical Engineers(ASME), a Fellow of Society for Design and Process Science (SDPS) and a Fellow and honorary member of The Academy of Transdisciplinary Learning \& Advanced Studies (TheATLAS). He is also an honorary member of International Center for Transdisciplinary Research (CIRET), France. He has published over 150 scientific papers that cover many engineering technical fields. He has been PI or Co-PI on over 40 funded research projects. Under his supervision more than $170 \mathrm{MS}$ and Ph.D. graduate students have received degrees.

Copyright (c) 2012 by the author. This is an open access article distributed under the Creative Commons Attribution License (https://creativecommons.org/licenses/by/4.0/), which permits unrestricted use, distribution, and reproduction in any medium, provided the original work is properly cited. 